standard no longer stimulates population but tends the opposite way; for the fourth, the extornal outlets are now largely self-producers. As regards the rapid introduction of new thingsthese mostly now demand increased leisure for their proper absorption and use, so that the two are co-related and mutually dependent.

It can be conceived that a socialistic organisation of society could obviate such of the maladjustments as depend upon gains and risks of absorption not being in the same hands, and a theoretical technique can be worked out for the most profitable rate of absorption of scientific invention, having regard to invested capital, and skill and local interests. It is sufficient to say that it needs a tour de force of assumptions to make it function without hopelessly impairing that central feature of economic progress, namely individual choice of the consumer in the direction of his demands, and an equally exalted view of the perfectibility of social organisation and political wisdom. But in the field of international relations and foreign trade, which alone can give full effect to scientific discovery, it demands qualities far beyond anything yet attainable.

Economic life must pay a heavy price, in this generation, for the ultimate gains of science, unless all classes become economically and socially minded, and there are large infusions of social direction and internationalism, carefully introduced. This does not mean government by scientific technique, technocracy, or any other transferred technique, appropriate as these may be to the physical task of production ; for human wills in the aggregate are behind distribution and consumption, and they can never be regulated by the principles which are so potent in mathematics, chemistry, physics, or even biology. Scientific workers may contribute much by sharing the problems of social science along its own lines, by giving a greater proportion of brilliant minds to this field and by planning research.

\title{
Atomic Transmutation
}

T WENTY-SIX years have passed since the British Association last met at Leicester in 1907, and the apparently stable world of a quarter of a century ago has altered almost out of recognition. These changes in political, moral and spiritual values are reflected in the world of physical science, which differs almost toto coelo from the structure raised by the labours of the nineteenth century and its predecessors. But even then rumblings were apparent, and it is a remarkable fact that the discussion on atomic transmutation, opened in Section A (Mathematics and Physics) by Lord Rutherford on September 11, had its antitype in a sectional discussion on the constitution of the atom opened by Prof. Emest Rutherford, as he then was, at the 1907 meeting, to which contributions were made by Lord Kelvin, Sir Oliver Lodge and Sir William Ramsay.

Lord Rutherford, whose contribution to the present discussion was a masterly review of a quarter of a century's work on atomic transmutation, remarked that, at the discussion which he opened in 1907, he indicated the importance of the transformations of radioactive bodies, and emphasised the difficulty of explaining the part played by positive electricity-we had then no inkling of a knowledge of the positive electron. $\mathrm{He}$ reminded the audience that Sir Oliver Lodge, who nevertheless proclaimed his belief in the electrical structure of the atom, had remarked that the opener was an adept in the art of skating on thin ice. Kelvin, who in 1904 was prepared to accept the notion of the transmutation of the radium atom, in 1907 did not find the evidence for transmutation satisfactory. It was about this period that Lodge, in a letter to the Times, suggested that if Kelvin would read the evidence he would change his opinion; Kelvin's reply was that he had read Rutherford's "Radioactivity" and remained unconvinced!

The work of the eighteenth and nineteenth century chemists had given to the world some eighty-odd elements, and it was quite clear that the atoms of the elements were very stable structures. But though the old ideas of transmutation were exploded, the problem still existed, and indeed had been clearly formulated by Faraday. The discovery of radioactivity showed that elements such as uranium and thorium were undergoing spontaneous transformation, and a large number of new elements were brought to light. Moreover, the property was shown to exist in a very slight degree in elements such as potassium and rubidium, the remainder of the normal elements being stable under ordinary conditions over periods to be reckoned in millions of years.

It was in 191.1 that the nuclear structure of the atom was clearly evidenced, and a little later that Bohr's masterly interpretation of the movements of electrons gave an explanation of spectral regularities. It soon became evident that outer electrons played no major part in transmutations, that the changes produced by stripping off electrons were only temporary in character, and that the structure of the nucleus must be changed if we wished to institute any permanent atomic transmutation. Moreover, evidence had accumulated to show that the nucleus was a very small entity.

If an $\alpha$-particle were fired at a nucleus, the enormous forces developed in a head-on collision might be expected to disturb the structure of the nucleus, and it was in 1919 that decisive experiments were made. When $\alpha$-particles were fired in oxygen, no effect was produced, but when they were fired in nitrogen, a new type of particle appeared-the proton. 
If we assume that the proton originated from a transformation of the nitrogen nucleus, the question of the rationale of the transmutation becomes urgent. Photographic evidence showed the capture by the nucleus of an $\alpha$-particle accompanied by the emission of a proton. If then a nitrogen nuclous of mass 14 and charge 7 , assimilates an $\alpha$-particlo of mass 4 and charge 2 , with the emission of a proton of mass 1 and charge 1 , we are loft with a nuclear structure of mass 17 and charge 8 -an isotope of oxygen, in fact. In a similar manner, other transmutations may be checked, remembering that all such changes must obey what may be termed general onergy conditions, that is, wo must take into account not only kinetic energy, but also the masses involved, romombering that, in some sense, mass and energy are convertible torms. It will be seen that in the instance considered, the new element has a mass throe units higher and a charge one unit higher than that of the element which has suffored transmutation.

Beryllium, of mass 9 and charge 4, when bombarded, captures an $\alpha$-particle of mass 4 and charge 2 , giving rise to a structure of mass 12 and charge 6 and emitting a neutron of mass 1 and charge zero.

It is not difficult to picture the changes which ensue when neutrons are fired into oxygen or nitrogen with the consoquent emission of an $\alpha$-particle, and indeed it is certain that future experiments will show that the neutron is a very powerful weapon of research. Five years ago it became evident that the methods of attack developed must be supplemented by the use of other types of fast particle if more information were to be forthcoming, and it was found possible to obtain from an electric discharge large supplies of particles the spoods of which might be raised by travel through an electric field. This demand has resulted in tho dovelopment of laboratory methods for the production of high potentials. Lately, assistance has been given by developments of wave mechanies which have shown that particles which could not surmount a potential barrier might yet got through, so that thero is a possibility of succossful attack by using intense streams of particles at low voltages. One timely word of warning was issued to those who look for sources of power in atomic transmutations-such expectations are the merest moonshine.

It was fortunato that Sir Oliver Lodge was able to be present at the discussion. His charming and rominiscent speech in moving a vote of thanks to Lord Ruthorford was a fitting tribute to a romarkable survey.

Space will not permit of the detailed consideration of the symposium which followed the opening address. As has been remarked, the nuclear theory developed by Gamow indicates the possibility of disintegrating the nuclei of tho lighter elements by protons having energios corresponding to a fow hundred thousand volts. Dr. J. D. Cockcroft and Dr. E. T. S. Walton described an apparatus capable of producing protons having energies of 700 kilovolts. With these protons they have disintegrated lithium, boron and fluorine, tho disintegration in every instance being accompanied by the ejection of an $\alpha$-particle. Lithium splits up into two $\alpha$-particles and boron into throe. Dr. M. L. Oliphant described experiments in which elements in a very pure state have been bombarded with protons and ions of 'heavy' hydrogen-the isotope of hydrogen of mass 2. The heavy eloments are not disintegrated appreciably by bombardment at energies bolow 220 kilovolts. The disintegration of lithium by protons and 'doutons' was described, the last-named particle being remarkably efficient as a disintegrating agont. Mr. P. I. Dee showed some remarkably interesting photographic tracks obtained with the expansion chamber, and Prof. P. M. S. Blackett developerd the story of the discovery and possible genesis of the positive electron, thus closing a symposium as striking as any of those that have boon associated in tho past with the work of Section A of the British Association.

A. F.

\section{Obituary}

Tine Riaht Hox. Viscount Grey of Fallodon, K.G., F.R.S.

$A^{\text {LThough the first Viscount Grey of }}$ A Fallodon, Northumberland, devoted nearly the whole of his life to political work, his death, on Soptember 7, at the age of sevonty-one years, has removed from ornithological circles, and bird protection bodies in particular, a keen and dovoted student.

Lord Grey's wild birds' sanctuary at Fallodon has become widely known and many are the naturalists who have benefited from his courtesy, and visited it. Waterfowl were Lord Groy's especial interest and the fact that for twolve years none of the foreign spocies bred at Fallodon were pinioned, but left to find their own nest-sites, hatch their own eggs and bring their broods on to the ponds unaided, living a perfectly wild existence excepting for wheat-feeding in morning and evening, the addition of a fox-proof fence and the destruction of stoats and rats, and in the case of the wood-ducks, the supplying of small barrels on the boughs to allow for the insufficiency of natural nesting holes in the trees, adds considerably to the scientific value of the observations.

In a paper read before the Berwickshire Naturalists' Club in 1921, Lord Grey doscribed the breoding of ten species of British duck, mallard, wigeon, pintail, shoveller, garganoy, teal, tufted duck, common pochard, red-crested and 